\title{
Management of hypertensive emergencies
}

\author{
J E Deal, T M Barratt, M J Dillon
}

\begin{abstract}
Between 1975 and 1985, 454 patients with hypertension were admitted to the Renal Unit of the Hospital for Sick Children. A total of $110(24 \%)$ patients presented with severely raised blood pressures deemed to require emergency management. At presentation 84/110 had symptoms and signs of long standing hypertension with neurological involvement. Between 1975 and 1980 bolus intravenous injections of diazoxide and/or hydralazine were used with the aim of reducing the blood pressure to within the normal range for age in the first 12-24 hours after admission. Of 57 patients treated in this way 13 developed hypotensive complications and four, whose blood pressures returned to normal within 24 hours of admission, suffered irreversible neurological damage. Subsequently the management changed to the use of intravenous infusions of labetalol (1-3 mg/kg/hour) and/or sodium nitroprusside $(0.5-8 \mu \mathrm{g} / \mathrm{kg} / \mathrm{min})$ to enable a more gradual controlled reduction of blood pressure over the first 96 hours of admission. Between 1980 and 1985, 53 patients were treated using this regimen. In all cases blood pressure reduction was achieved in a more controlled manner without further neurological impairment or serious irreversible side effects.
\end{abstract}

From our experience, the use of labetalol and sodium nitroprusside by incremental infusion in the critical early phase of management has resulted in improved control of accelerated hypertension without the sudden hypotensive episodes seen when bolus injections are used.

\section{(Arch Dis Child 1992;67:1089-92)}

There is a tendency in the treatment of hypertensive emergencies, supported by many textbooks and leading articles, to aim for as fast a reduction in blood pressure as possible in order to avoid the potentially dangerous and life threatening complications of high blood pressure. Many textbooks still advocate rapid blood pressure reduction using bolus treatment with intravenous or intramuscular injections of antihypertensive drugs and, more recently, sublingual preparations aiming to bring the blood pressure down to normal levels as quickly as possible. However, Ledingham and Rajagopalan reported in 1979 the occurrence of permanent neurological deficits in adults treated with bolus antihypertensive therapy resulting in rapid blood pressure reduction. ${ }^{1}$ As a result they advocated the use of controlled blood pressure reduction by the use of infusion treatment. Permanent neurological damage has also been reported in children treated for hypertension ${ }^{2} 3$ and infusion treatment has been advocated for the treatment of accelerated hypertension in them. ${ }^{4} \mathrm{We}$ therefore reviewed our treatment of hypertensive emergencies and report here our experience over 10 years comparing the use of bolus treatment and incremental intravenous infusion treatment in children.

The level of systolic or diastolic blood pressure at which children who are at risk of hypertensive complications can be distinguished from those who are not at risk can not of itself be defined. Symptoms and signs of a hypertensive emergency are non-specific and the assessment of the need for urgent treatment depends upon a clinical assessment of the degree and rate of rise of blood pressure and the potential for end organ damage or loss of life in each individual child. Severe hypertension is defined as a blood pressure greater than the 99th centile for age and sex. Accelerated hypertension has been defined as a blood pressure greater than the 95th centile for age and sex in which there is evidence of end organ damage or dysfunction with fibrinoid necrosis of arterioles and signs of grade III hypertensive retinopathy. ${ }^{5}$

\section{Patients and methods}

Before 1980 children presenting with a hypertensive emergency to our unit were treated with bolus intravenous diazoxide $(3-5 \mathrm{mg} / \mathrm{kg} /$ dose) and/or intramuscular hydralazine $(0.2-0.4 \mathrm{mg} /$ $\mathrm{kg} /$ dose) aiming for as rapid a reduction in blood pressure to normal as was possible. Since 1980 children with a hypertensive emergency have been managed with incremental intravenous infusions of labetalol and/or sodium nitroprusside, aiming to reduce the blood pressure in the first $\mathbf{2 4}$ hours by only a third of the eventual blood pressure reduction desired. The target blood pressure was the 95th centile systolic value for age and sex for each child obtained from the American Task Force data. ${ }^{5}$

Between 1975 and 1985, 454 children who were referred to the Renal Unit at the Hospital for Sick Children, London were hypertensive. A total of $110(24 \%)$ presented with severe hypertension deemed to require emergency management. Fifty seven presented between 1975 and 1980 and received bolus treatment, and 53 presented between 1980 and 1985 and received infusion treatment. These two groups of children were reviewed retrospectively and the outcome and any complications of treatment compared. 
Details of the two groups are shown in table 1. Group 1 received boluses of diazoxide (3-5 $\mathrm{mg} / \mathrm{kg} /$ dose intravenously) and/or hydralazine $(0 \cdot 2-0.4 \mathrm{mg} / \mathrm{kg} / \mathrm{dose}$ intramuscularly) until their blood pressure had returned to 'normal'. Group 2 were treated with incremental intravenous infusions of labetalol (1-3 mg/kg/hour) and/or sodium nitroprusside $(0.5-8 \mu \mathrm{g} / \mathrm{kg} / \mathrm{min})$ aiming for a third of the eventual blood pressure reduction desired in the first 24 hours. The dose of labetalol or sodium nitroprusside was titrated in increments according to the child's blood pressure. Normal saline was administered in boluses of $50 \mathrm{ml}$ if the blood pressure fell below the lower limit of blood pressure that had been set for each child. The blood pressure was measured by nursing staff at 5 minute intervals while the infusion was running and at 15 minute intervals when the infusion was temporarily discontinued; changes in the infusion rate were only made after two consistent readings of blood pressure had been obtained. Neurological observations including pupillary responses to light were recorded regularly. Labetalol was avoided in any child who had signs of cardiac failure and/or had a history of asthma. Monitoring of plasma cyanide concentrations of those children who received sodium nitroprusside for longer than 48 hours was performed and no signs of toxicity occurred in our patients.

\section{Results}

Children in both treatment groups were comparable in terms of age, initial blood pressure, and underlying diagnosis (tables 1 and 2). Altogether 84/110 children at presentation had symptoms and signs suggestive of accelerated hypertension (44 in the bolus group, 40 in the infusion group) with end organ damage such as hypertensive retinopathy and/or left ventricular hypertrophy. They all gave histories of symptoms attributable to hypertension, for example

Table 1 Clinical details of 110 children treated for accelerated hypertension. Results are mean $(S D)$

\begin{tabular}{|c|c|c|}
\hline & $\underset{(n=57)}{\text { Group }} 1$ & $\begin{array}{l}\text { Group } 2 \\
(n=53)\end{array}$ \\
\hline $\begin{array}{l}\text { Age (years) } \\
\text { Range } \\
\text { Systolic blood pressure }(\mathrm{mm} \mathrm{Hg}) \\
\text { Range } \\
\text { Diastolic blood pressure }(\mathrm{mm} \mathrm{Hg}) \\
\text { Range } \\
\text { Male:female }\end{array}$ & $\begin{array}{l}8 \cdot 04(4 \cdot 15) \\
0 \cdot 08-14 \cdot 58 \\
181(40 \cdot 5) \\
115-300 \\
127 \cdot 0(34 \cdot 3) \\
80-230 \\
33: 24\end{array}$ & $\begin{array}{l}7 \cdot 97(4 \cdot 53) \\
0 \cdot 08-17 \cdot 00 \\
179(37 \cdot 1) \\
120-260 \\
127 \cdot 5(36 \cdot 5) \\
60-215 \\
31: 22\end{array}$ \\
\hline
\end{tabular}

There were no significant differences between the variables by Student's $t$ test.

Table 2 Causes of hypertension in 110 children treated for accelerated hypertension between 1975-1985

\begin{tabular}{lcc}
\hline Diagnosis & $\begin{array}{l}\text { Group I } \\
(n=57)\end{array}$ & $\begin{array}{c}\text { Group 2 } \\
(n=53)\end{array}$ \\
\hline Reflux nephropathy & 16 & 12 \\
Obstructive uropathy & 7 & 5 \\
Renovascular disease & 6 & 10 \\
Glomerular disease & 10 & 8 \\
Polycystic renal disease & 1 & 2 \\
Haemolytic uraemic syndrome & 2 & 6 \\
Coarctation & 2 & 2 \\
Phaeochromocytoma & 0 & 2 \\
Wilms' tumour & 2 & 0 \\
Renal dysplasia & 3 & 2 \\
Miscellaneous & 8 & 4 \\
\hline
\end{tabular}

headaches and visual problems, that had been present for weeks or months before admission. Their admissions were often prompted by the development of neurological symptoms and signs (table 3): 28 of the children presented with hypertensive encephalopathy. Although more group 1 children had a facial palsy or signs of a hemiplegia at presentation, the differences were not statistically significant. Twenty six of the 110 did not have evidence of sustained hypertension but had severely raised blood pressures and were treated with parenteral therapy to prevent the occurrence of acute hypertensive complications.

Fifty seven children were treated with intravenous diazoxide, 16 of these also received intramuscular hydralazine. Thirteen of the 57 children in group 1 developed hypertensive complications associated with the rapid reduction of their blood pressures (see table 4). In nine these complications were transient with recovery of visual and renal function to pretreatment levels, but in four patients the neurological damage sustained during treatment was permanent (table 5). ${ }^{2} 3$ These four patients were all subsequently diagnosed as having reflux nephropathy. Only one of them had previously had urinary tract infection diagnosed and none was previously known to have renal impairment. On admission they were all severely hypertensive with long standing hypertensive symptoms and evidence of sustained disease with end

Table 3 Symptoms and signs at presentation

\begin{tabular}{|c|c|c|}
\hline & $\underset{(n=57)}{\text { Group I }}$ & $\begin{array}{l}\text { Group 2 } \\
(n=53)\end{array}$ \\
\hline Visual symptoms & 6 & 4 \\
\hline Facial palsy & 9 & 4 \\
\hline Convulsions & 15 & 13 \\
\hline Hypertensive retinopathy & 16 & 14 \\
\hline Hypertensive encephalopathy & 15 & 13 \\
\hline Hemiplegia & 6 & 3 \\
\hline Left ventricular hypertrophy & 9 & 5 \\
\hline Cranial bruits & 2 & 4 \\
\hline $\begin{array}{l}\text { Blood pressure }>99 \text { th centile } \\
\text { without end organ damage }\end{array}$ & 13 & 13 \\
\hline
\end{tabular}

Table 4 Signs and symptoms developed during emergency treatment of hypertension

\begin{tabular}{lcc}
\hline Complication & $\begin{array}{l}\text { Group } I \\
(n=13)\end{array}$ & $\begin{array}{l}\text { Group 2 } \\
(n=2)\end{array}$ \\
\hline Transient visual loss & 6 & 0 \\
Transient acute renal failure & 5 & 2 \\
Permanent visual loss & 4 & 0 \\
Transverse ischaemic myelopathy & 1 & 0 \\
\hline
\end{tabular}

Table 5 Details of four patients with permanent neurological damage

\begin{tabular}{lll}
\hline $\begin{array}{l}\text { Patient } \\
\text { No }\end{array}$ & $\begin{array}{l}\text { Blood pressure } \\
\text { change in } \\
\text { frst } 24 \text { hours } \\
(\mathrm{mm} \mathrm{Hg})\end{array}$ & \begin{tabular}{c} 
Complication \\
\hline 1
\end{tabular} \\
\hline$\frac{260}{190} \rightarrow \frac{120}{60}$ & $\begin{array}{l}\text { Permanent bilateral visual field } \\
\text { losses }\end{array}$ \\
\hline 3 & $\frac{285}{230} \rightarrow \frac{90}{60}$ & $\begin{array}{c}\text { Permanent bilateral visual field } \\
\text { losses; transient acute renal } \\
\text { failure; transverse ischaemic } \\
\text { myelopathy }\end{array}$ \\
4 & $\frac{200}{130} \rightarrow \frac{160}{80}$ & $\begin{array}{c}\text { Permanent unilateral visual loss; } \\
\text { bilateral VIth nerve palsies } \\
\text { Permanent bilateral visual loss }\end{array}$ \\
\hline
\end{tabular}


organ changes, that is hypertensive retinopathy and left ventricular hypertrophy. Three of these four patients had a facial palsy present before admission that had not been investigated and all were encephalopathic. Their hypertension was successfully treated with intravenous boluses of diazoxide but with the reduction in their blood pressures they showed deterioration in their neurological signs with loss of pupillary light responses and decreased levels of consciousness. One child also developed transient acute renal failure requiring peritoneal dialysis and developed a transverse ischaemic myelopathy. Despite stellate ganglion block to improve ciliary artery blood flow and measures to raise the blood pressure in all four patients there was no improvement in visual or neurological function. Subsequent investigations showed evidence of anterior ischaemic optic neuropathy. ${ }^{3}$ All four patients are now severely visually handicapped and one is also paraplegic.

Fifty three children were treated with incremental hypotensive infusions: 25 with labetalol alone, 12 with sodium nitroprusside alone because of concern for their cardiac function or a history of reversible airway disease, or the need for a vasodilator in addition to an antihypertensive agent, and 16 children received both labetalol and sodium nitroprusside because of difficulties controlling their blood pressure with a single agent. Only two of these 53 children developed hypotensive complications: transient acute renal failure which required peritoneal dialysis. No patients developed new neurological signs or visual problems and no hypertensive complications occurred once treatment had started. Blood pressure control was achieved in all patients with clinical improvement of their hypertensive signs and symptoms. Infusions were well tolerated, but intensive nursing was required, particularly during the first three days of admission, to achieve a smooth, controlled reduction in blood pressure.

\section{Discussion}

These results show that hypertensive emergencies in children can be successfully treated by incremental infusion treatment. Bolus treatment and rapid blood pressure reduction was associated with a higher incidence of permanent neurological sequelae and should therefore be avoided in any child who presents with severe hypertension, particularly if there are symptoms and/or signs suggestive of long standing hypertension. These two groups of children had similar signs and symptoms at presentation and had similar degrees of hypertension. Differences between the groups occurred in the rapidity with which the blood pressures were reduced and the treatment methods that were used to achieve this. Children managed by incremental infusion were monitored much more closely during their treatment so that sudden drops in blood pressure did not occur and any changes in neurological signs were quickly appreciated.

Some children in both groups already had signs of neurological damage, secondary to their hypertension, at presentation. Further deterior- ation in neurological status was associated with the rapid and uncontrolled blood pressure reduction that occurred with the use of bolus treatment, no permanent sequelae being seen in the children managed with infusion hypotensive treatment. Although there were no statistically significant differences between the children in groups 1 and 2 in the incidence of neurological signs and symptoms at presentation, it may be that children in group 1 had longer standing hypertension and hence were more prone to the development of hypotensive complications.

There is a recognised association between the presence of renal artery stenosis and arterial disease affecting the cerebral circulation, ${ }^{6}$ which might account for an increased risk of complications occurring with blood pressure reduction; however, more children in group 2 were found to have renovascular disease than in group 1.

In severe hypertension from whatever cause, initial vasoconstriction occurs with subsequent arteriolar fibrinoid necrosis, blood vessel wall thickening and fibrosis, hypertrophy of the intima and media, and loss of relative elasticity with a subsequent reduction in intraluminal diameter. $^{7}$ After a while the vessel changes become fixed and blood vessels cannot easily dilate or react to changes in blood flow, especially relative hypotension. These changes are particularly important in the cerebral vasculature with loss of cerebral blood flow autoregulation. ${ }^{8}$ If blood pressure in that situation is rapidly reduced the cerebral vasculature cannot dilate to ensure adequate cerebral perfusion and ischaemia occurs, particularly of watershed areas of the cerebrum and cerebellum such as the visual cortex and areas supplied by end arteries in the central nervous system, for example spinal arteries and ciliary arteries supplying the optic nerve. Although there are justifiable concerns to prevent the complications of hypertension such as cerebral haemorrhage, too rapid blood pressure reduction can be more harmful in a circulation that has 'adjusted' to the hypertensive state.

The key to safe blood pressure reduction is probably not which drug is used but its method of administration and the rapidity with which blood pressure falls. Frequent monitoring of the child's blood pressure, as it is reduced, so that the blood pressure can be quickly raised using intravenous saline should relative hypotension occur; monitoring of pupillary responses to detect the first signs of visual compromise; and slow controlled blood pressure reduction are all vital to the successful treatment of hypertensive emergencies. Incremental infusion treatment allows these criteria to be met. Bolus treatment by whatever route is dangerous if the blood pressure is not monitored adequately as unpredictable and sustained drops in pressure can occur.

Sublingual nifedipine has been increasingly advocated for use in hypertensive emergencies, ${ }^{10}$ but as with bolus diazoxide or hydralazine its effect and duration of action are unpredictable and similar hypotensive complications could occur. ${ }^{11}$ The use of sublingual nifedipine, administered without intravenous access in severe hypertension, cannot be 
recommended for these reasons, although it may have some role if appropriate precautions are taken.

More recently oral and sublingual captopril have been reported to be effective in hypertensive emergencies with few side effects. ${ }^{12} 13$ Children have a more active renin-angiotensin system than adults ${ }^{14}$ and a higher incidence of renal artery stenosis as a cause of severe hypertension, ${ }^{15}$ both of which contraindicate the use of an angiotensin converting enzyme inhibitor as first line treatment when the underlying cause and disease duration are unknown. Oral captopril, however, has been reported to be effective in a child with haemolytic uraemic syndrome in whom the hypertension was acute and resistant to treatment with other antihypertensives. ${ }^{16}$ The use of other oral drugs might allow blood pressure to be reduced gradually but in children with accelerated hypertension drug absorption, onset of action, and duration of action are all unpredictable and the use of the oral route would not obviate the need for close monitoring and intravenous access to allow rapid blood pressure elevation with saline infusion should relative hypotension occur.

The use of incremental infusions of labetalol for the treatment of accelerated hypertension has been reported to be effective in adults without hypotensive complications, ${ }^{17} 18$ but no reports exist of its use in the emergency management of children. Sodium nitroprusside has been used for the treatment of severe hypertension in adults and children with good clinical effect and without hypotensive complications or problems with cyanide toxicity. ${ }^{19} 20$ The use of incremental infusions, however, requires skilled nursing care and frequent monitoring of blood pressure. The onset of accelerated hypertension is a medical emergency and such labour intensive treatment is justified in order to prevent both further hypertensive and hypotensive complications.

The incidence of severe and accelerated hypertension has decreased over the last 10 years with increasing recognition of the early signs and symptoms of high blood pressure in childhood. Better recognition, investigation, and management of children with a history of urinary tract infections, follow up of children with renal disease and reflux nephropathy, and the appreciation of the diverse way in which hypertension can present in the young should prevent children from presenting with a hypertensive emergency. However, when a child with severe hypertension does present, a careful clinical assessment particularly noting any signs or symptoms indicative of long standing hypertension and any features suggestive of renovascular disease and associated intracerebral vascular disease should be identified as well as signs of end organ damage and impending cardiac failure. Only then can the decision be made concerning the rapidity of blood pressure reduction and the most appropriate drugs to be used. In any child with sustained severe hypertension, particularly with neurological symptoms and signs, we would recommend that the blood pressure should be reduced by incremental infusion of short acting drugs such as labetalol or sodium nitroprusside lowering the blood pressure in a controlled manner over the first 96 hours of admission and avoiding the unpredictable, relative hypotension seen with bolus treatment and thereby maintaining adequate cerebral and renal blood flows.

JD was supported by the Charlotte Parkinson Research Fund and John Herring and Friends (Child Health Research Appeal Trust).

1 Ledingham JGG, Rajagopalan B. Cerebral complications in the treatment of accelerated hypertension. $Q \mathcal{F}$ Med 1979 189:25-41.

2 Hulse JA, Taylor DSI, Dillon MJ. Blindness and paraplegia in accelerated hypertension. Lancet 1979;ii:553-6.

3 Taylor D, Ramsay J, Day S, Dillon M. Infarction of the optic nerve head in children with accelarated hypertension. $\mathrm{Br} \mathcal{J}$ Ophthalmol 1981;65:153-60.

4 Dillon MJ. Modern management of hypertension. In: Meadow SR, ed. Recent advances in paediatrics. No 7 . Edinburgh: Churchill Livingstone, 1984:35-55.

5 Report of the second task force on blood pressure control in children. Pediatrics 1987;79:1-25.

6 Dillon MJ. Renovascular hypertension: association with cere brosvascular disease and comparison of investigative procedure. In: Brodehl J, Ehrlich JHH, eds. Paediatric procedure. In: Brodehl J, Ehrlich JHH, eds. P
nephrology. Berlin: Springer-Verlag 1984:378-81.

7 Calhoun DA, Oparil S. Current concepts; treatment of hypertensive crisis. N Engl f Med 1990;323:1177-83.

8 Strandgaard S, Olesen J, Skinhøi E, Lassen NA. Autoregulation of brain circulation in severe arterial hyperten sion. BMY 1973;i:507-10.

9 Dilmen U, Caglar MK, Senses DA, Kinik E. Nifedipine in hypertensive emergencies of children. Am $\mathcal{F}$ Dis Child 1983; 137:1162-5.

10 Bertel O, Conen D, Radu EW, Muller J, Lang C. Dubach UC. Nifedipine in hypertensive emergencies. BMF 1983 286:19-21.

11 Wachter RM. Symptomatic hypotension induced by nifedipine in the acute treatment of severe hypertension. Arch Intern Med 1987;147:556-8.

12 Angeli P, Chieza M, Caregaro L, et al. Comparison of sublingual captopril and nifedipine in immediate treatment of hypertensive emergencies. Arch Intern Med 1991;151: of hypert.

13 Hauger-Klevene JH. Captopril in hypertensive crisis. Lancet 1985;ii:732-3.

14 Dillon MJ, Ryness JM. Plasma renin activity and aldosterone concentration in children. $B M \mathcal{F}$ 1975; iv:316-9.

15 Deal JE, Snell MF, Barratt TM, Dillon MJ. Renovascular disease in childhood. $\mathcal{J}$ Pediatr 1992 (in press)

16 Griswold W, McNeal R, O'Connor D, Reznik V, Mendoza S Oral converting enzyme inhibitor in malignant hypertension. Arch Dis Child 1982;57:235-7.

17 Cumming AM, Davies DL. Intravenous labetalol in hypertensive emergency. Lancet 1979;i:929-30.

18 Cressman MD, Vidt DG, Gifford RW, Moore WS, Wison DJ. Intravenous labetalol in the management of severe hypertension and hypertensive emergencies. Am Heart $\mathcal{J}$ 1984;107:980-5.

19 Gordillo-Paniagua G, Velasquez-Jones L, Martini R, ValdesBolanos E. Sodium nitroprusside treatment of severe Bolanos E. Sodium nitroprusside treatment of severe
arterial hypertension in children. $\mathcal{f}$ Pediatr 1975;87: arterial $799-802$.

20 Luderer JR, Hayes AH, Dubynsky O, Berlin CM. Long-term administration of sodium nitroprusside in childhood. 